\title{
Underwater Abrasion Resistance of Cementitious Acrylic Coating on Repaired Surface of Concrete Dam and Stilling Basin
}

\author{
Jakob Šušteršič ${ }^{1, *}$, Andrej Kryžanowski ${ }^{2}$, Aleš Brodnik $^{1, *}$, and Andrej Zajc ${ }^{1}$ \\ ${ }^{1}$ IRMA Institute for Research in Materials and Applications, Slovenčeva 95, 1000 Ljubljana, Slovenia \\ ${ }^{2}$ University of Ljubljana, Faculty of Civil and Geodetic Engineering, Department of Environmental Civil Engineering, Jamova 2, 1000 \\ Ljubljana, Slovenia
}

\begin{abstract}
The paper presents and analyzes the results of the underwater abrasion tests of Cementitious Acrylic Coating (CAC), which was used to protect the repaired surface of concrete dam and stilling basin of power-plant Moste on river Sava in Slovenia. Behavior of the CAC obtained with laboratory tests is rather similar to the behavior obtained after 1 year of application on the power-plant. Relatively good underwater abrasion resistance of CAC was obtained. Results of bond strength show that pressure of capillary water decreases bond between CAC and concrete surface. If such coating is additional loaded with abrasion forces, bond between those two layers becomes worse. Similar conclusions can be made on the basis of the obtained results of surface resistance to freeze-thaw test of CAC has been carried out. The resistance is rather good, but CAC separated from concrete surface, when water is present in the interface between the CAC and concrete surface during freeze-thaw loading.
\end{abstract}

\section{Introduction}

Concrete surfaces of dam and stilling basin of powerplant Moste on river Sava in Slovenia were damaged mainly due to underwater abrasion caused by waterborne particles, as well as due to freezing/thawing and weathering. All damaged concrete was removed and replaced by patching with trowel-applied polymercement mortar (PCM) and spraying-on new PCM layers. Thus repaired surfaces were additionally protected by the Cementitious Acrylic Coating (CAC). The investor wanted to use CAC in order to reduce the rate of deterioration at the repaired concrete surfaces and to cover the repaired patches, thus achieving a uniform appearance of the surfaces (Figure 1).

Acrylic latexes are designed to improve specific properties of cement mixtures such as adhesion, abrasion resistance, impact strength, flexural strength, and resistance to permeability. Acrylic latex - modified hydraulic - cement mortars are used primarily in thin coatings for concrete restoration [1].

CAC is a two component flexible cementitious, mineral-based waterproofing slurry, which was applied manually by a brush to previously cleaned and damp surfaces in two layers. Thickness of the CAC was measured on the different locations of repaired surfaces. Its values were in the range from $0.69 \mathrm{~mm}$ up to 2.09 $\mathrm{mm}$. Average thickness of the applied CAC on the site is $1.20 \mathrm{~mm}$

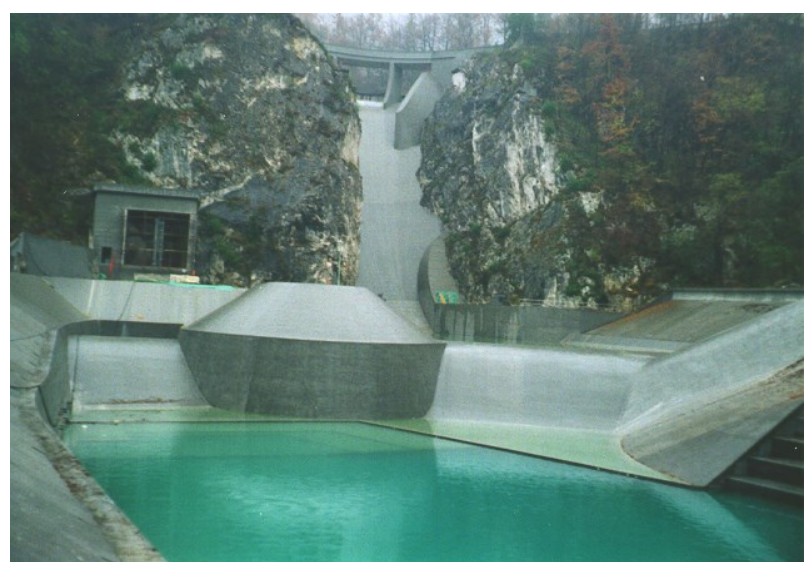

Fig. 1. Recovered repaired surfaces of concrete dam and stilling basin of the power-plant with the CAC.

Once the repair work was completed, the Investor proposed that an evaluation of the durability of the applied CAC, in particular the evaluation of its resistance to underwater abrasion, should be made at our Institute IRMA. The evaluation was based on the results obtained from the investigations. Some investigations were carried out on the site, and most of them were carried out in the laboratory of the Institute.

\section{Mechanical properties of CAC}

Compressive and flexural strengths and post-crack behavior in bending of the $\mathrm{CAC}$ were tested on the

* Corresponding author: jakob.sustersic@irma.si 
prisms with dimensions of $40 \times 40 \times 160 \mathrm{~mm}$ at the age of 28 and 120 days. Three point bending configuration has been used for determination of flexural strength and post-crack behavior. Span length was $100 \mathrm{~mm}$ (Figures 2 and 3). After bending test, compressive strengths were obtained on all halves of prisms (on the cubes with edge length of $40 \mathrm{~mm}$ ).

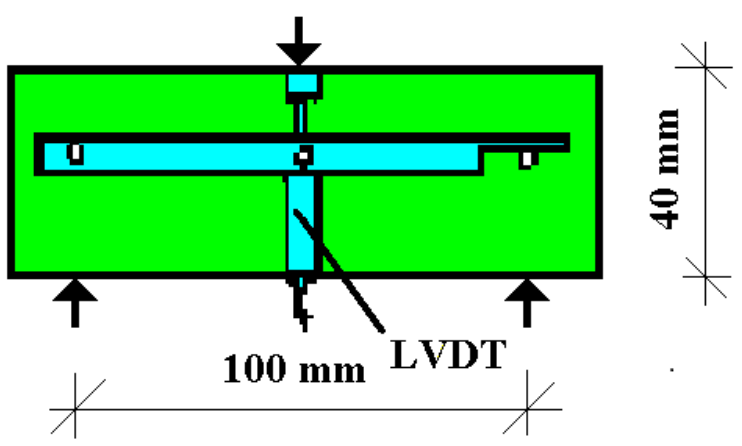

Fig. 2. Three point bending configuration of the test

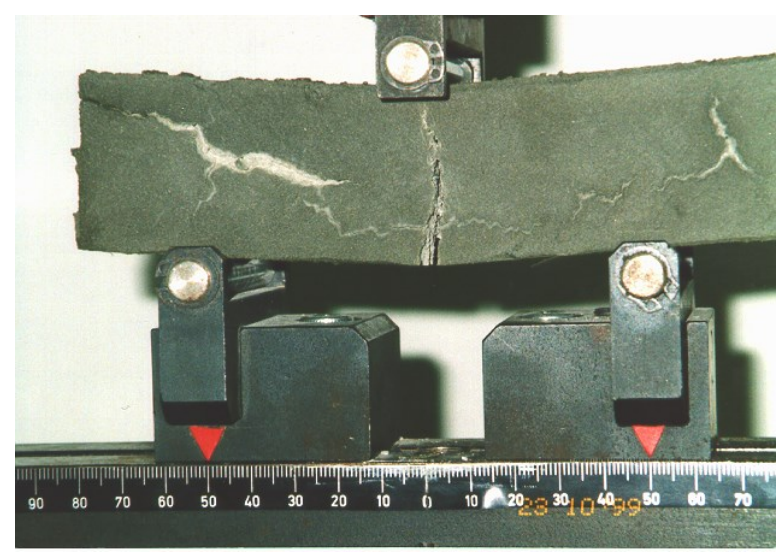

Fig. 3. Specimen after bending test of 28 day old CAC

Significant increase of compressive strength was obtained with regard to age of the CAC. Average compressive strength at the age of 28 days (which was $6,5 \mathrm{MPa}$ ) increased on the average value of $10,7 \mathrm{MPa}$ at the age of 120 days. Ultimate flexural strength remained unchangeable, more or less with regard to age of the CAC. Average values of $2,5 \mathrm{MPa}$, approximately are the same at 28 days and at 120 days. While, post-crack behavior in bending has been changed, so that area under load - deflection curves decreased at the age of 120 days in comparison with those obtained at the age of 28 days (Figure 4).

Area under load - deflection curve represents absorption energy. When first crack appears, fracture process continues only in the failure zone, which is located around first crack (Figure 3).

Area under load - deflection curve from first crack up to the end of curve represents absorption energy of failure zone $\left(\mathrm{W}_{\mathrm{FZ}}\right)$. If this area increases, absorption energy, toughness and ductility, respectively increase too. The ductility of the CAC can be estimated with a characteristic deflection $\left(\Delta_{\delta}\right)$ with respect to the deflection at first crack $\left(\delta_{\mathrm{FC}}\right) . \Delta_{\delta}$ is expressed by the equation (1)

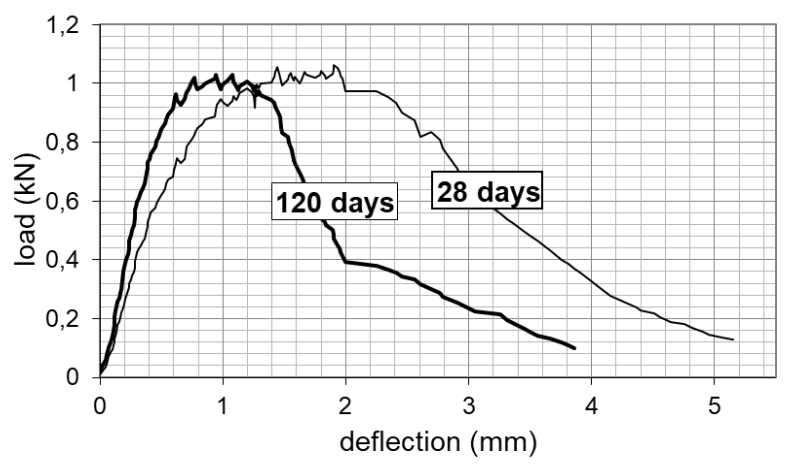

Fig. 4. Typical load - deflection curves of the CAC at the age of 28 and 120 days

$$
\Delta_{\delta}=W_{F Z} / F_{F C}
$$

where:

$\Delta_{\delta} \ldots \quad$ characteristic deflection ( $\left.\mathrm{mm}\right)$,

$\mathrm{W}_{\mathrm{FZ}} \ldots$... absorption energy of failure zone $(\mathrm{Nmm})$,

$\mathrm{F}_{\mathrm{FC}} \ldots$ load at first $\operatorname{crack}(\mathrm{N})$.

Material or composite is ductile if $\Delta_{\delta}>\delta_{\mathrm{FC}}$. The obtained average values of $\Delta_{\delta}$ and $\delta_{\mathrm{FC}}$ at the age of CAC: - 28 days: $\Delta_{\delta}=2.39 \mathrm{~mm}>\delta_{\mathrm{FC}}=0.78 \mathrm{~mm}$,

- 120 days: $\Delta_{\delta}=1.36 \mathrm{~mm}>\delta_{\mathrm{FC}}=0.61 \mathrm{~mm}$.

CAC is ductile at both ages, but decreases with age. Obtained results of measured mechanical properties of the $\mathrm{CAC}$ show, that strengths increase or remain equal, more or less in regard to aging, but its ductility decreases simultaneously.

\section{Underwater abrasion resistance of CAC}

Underwater abrasion resistance is the ability of concrete to withstand abrasion loads which are caused by water flow containing solid water borne particles. The effects of water borne abrasion are well demonstrated with the experimental method which is similar to standard ASTM C 1138. This method was developed in Structures Laboratory, U.S. Army Engineer Waterways Experiment Station $[2,3]$.

Underwater abrasion resistance of different concrete and mortars was already evaluated by this method: different concrete types (concrete with different w/c ratio) and polymer concrete [2, 3], concrete placed underwater [4], fiber reinforced concrete [2, 5 - 7], silica fume - mortars without and with fibres [8], polymer modified concrete without and with fibres [9, 10], polymer concrete and latex modified concrete with granulated rubber [11], concrete with different aggregate types and concrete with different types of surface treatment $[2,3]$.

The test method is designed to duplicate the abrasive action of waterborne particles in the stilling basins. Circulating water moves the steel grinding balls on the surface of a concrete sample, producing the desired 
abrasion effects. The water velocity and agitation effect are not sufficient to lift the steel balls off the surface of the concrete sample to cause any significant impact action against the surface. The test method can only be used to determine the relative resistance of the material to the abrasion action of waterborne particles.

The standard procedure of the investigation provides for the measurement of the wear of specimen surface at 12-hour intervals; the total investigation time is 72 hours. The result of the test is the average depth of abrasion $\left(\mathrm{ADA}_{t}\right)$ expressed by the average volume of wear on the surface of the specimen in the duration of the test:

$$
A D A_{t}=V L_{t} / A_{\text {spec }}
$$

where:

$\mathrm{ADA}_{t} \ldots$ average depth of abrasion after a specified duration of the test $t$

$\mathrm{VL}_{\mathrm{t}} \ldots$. . volume of lost material due to abrasion after a specified duration of the test $t$

$A_{\text {spec }} \ldots$ surface of the specimen exposed to underwater abrasion

$\mathrm{VL}_{t}$ is the difference in the volume of the specimen before the test and the volume of the specimen after a specified duration of the test. The volumes are determined on the basis of the weighing of the specimen in air and under water. However, since the loss of CAC is considerably lower than that of the concrete specimen, the CAC underwater abrasion resistance cannot be determined on the basis of the calculated $\mathrm{ADA}_{\mathrm{t}}$. It was determined on the basis of the measured portion of the surface of the CAC removed with respect to the total surface of the specimen exposed to underwater abrasion, which was covered by CAC.

\subsection{Preparation of test specimens}

Underwater abrasion resistance is tested on the specimen in the shape of a cylinder with the diameter of $29.5 \mathrm{~cm}$ and $10 \mathrm{~cm}$ thick. The specimens were prepared from concrete with similar characteristics to the concrete of the dam and stilling basin of power-plant Moste. The CAC was applied to the upper surfaces of the specimens in a similar way as on the site in two layers. The average CAC thickness was $1.2 \mathrm{~mm}$ similar to that of the CAC applied on repaired surfaces on the site.

\subsection{Results of underwater abrasion tests of CAC and correlations with some other properties of CAC}

\subsubsection{Influence of age of CAC on underwater abrasion resistance and correlation with ductility}

The tests were carried out 33 and 102 days after application of the CAC on preliminary prepared surface of concrete specimens. Surface portions of removed CAC, measured at 12 hour intervals, are shown in Figure 5 .
It has been found that underwater abrasion resistance decreases (the portion of removed CAC increases) by increasing the age of CAC. The 33-day-old CAC began to be removed on the edge of the specimen after 48 hours of abrasion loading (Figure 6).

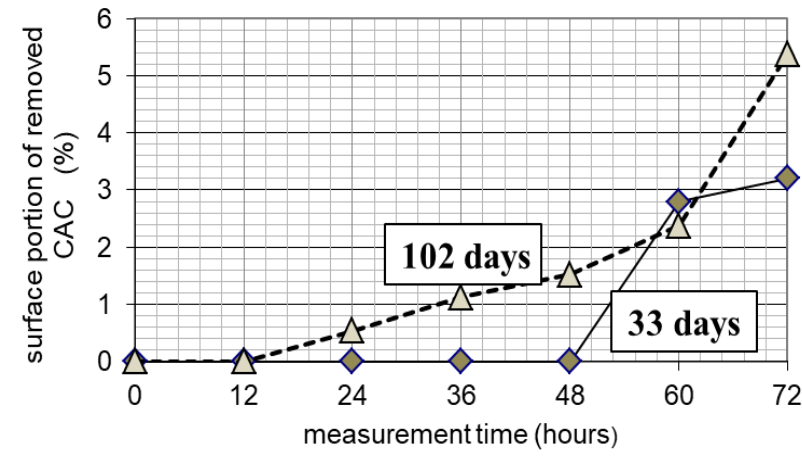

Fig. 5. Influence of $\mathrm{CAC}$ age on underwater abrasion resistance

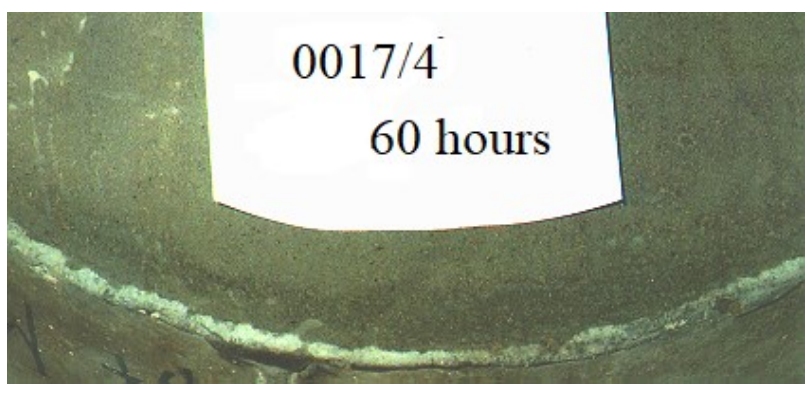

Fig. 6. Removed 33-day old CAC at the edge of the specimen after 60 hours of abrasion loading

While the 102-day-old CAC had already begun to be removed after 12 hours of the test, and then continued until the end of the test for up to 72 hours, when the surface portion of the removed CAC was 5,4\% (Figure 5 and 7).

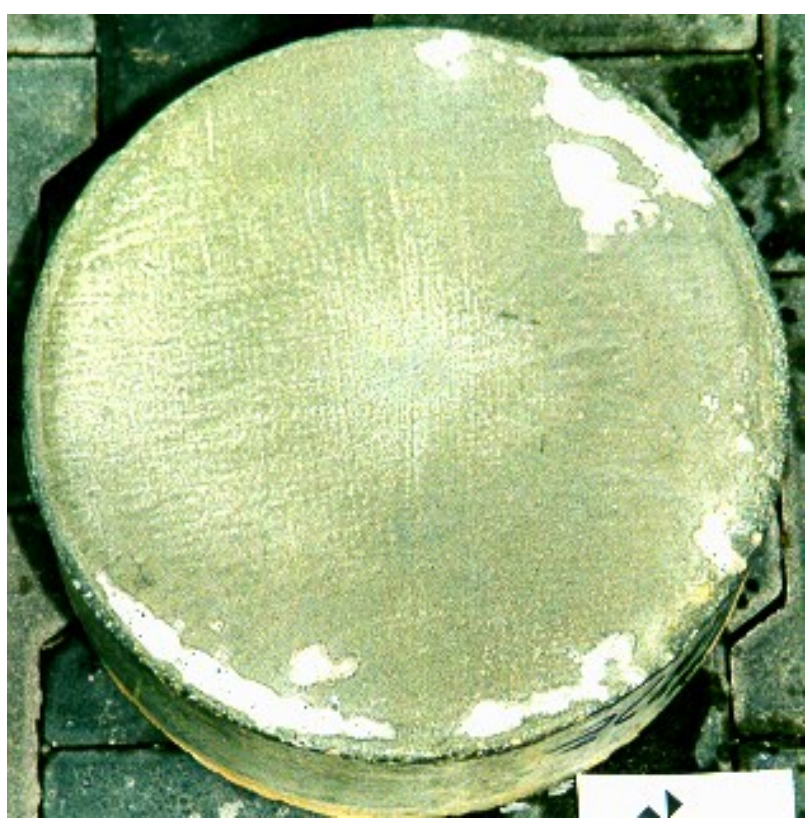

Fig. 7. The 102-day old CAC at the end of the test (5.4\% of entire surface of CAC was removed) 
The results obtained show that there is a correlation between underwater abrasion resistance and ductility of CAC. The ductility and underwater abrasion resistance of CAC decrease with its age (the surface portion of the removed CAC increases), as shown schematically in Figure 8.

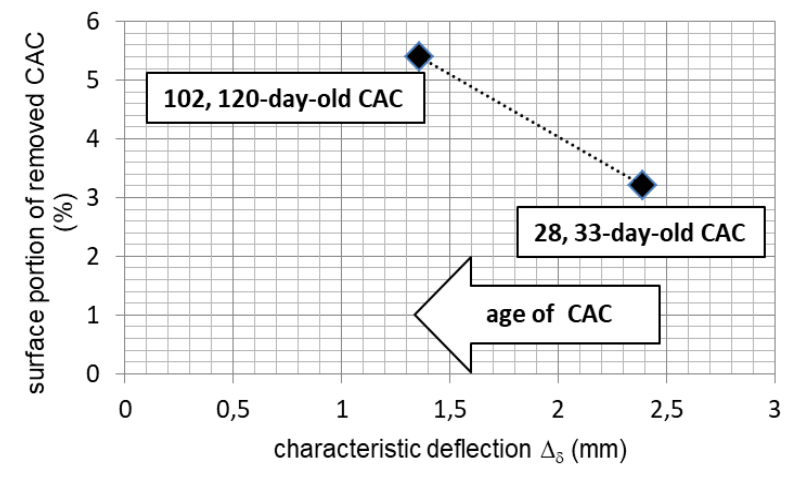

Fig. 8. Influence of CAC's age on underwater abrasion resistance and ductility

\subsubsection{Comparison between the results of the grinding wear test and the underwater abrasion test of CAC}

Relatively good grinding wear resistance $\mathrm{A}\left(\mathrm{cm}^{3} / 50 \mathrm{~cm}^{2}\right)$ of the 44-day-old CAC was obtained with the Böhme test method, which is given in EN 13892-3. This test simulates the grinding by means of an abrasive sand that is applied between the specimen and rotating disc. The test was carried out on three cubes with an edge of 7,07 $\mathrm{cm}$ so that the surface area with the CAC (test surface) was $50 \mathrm{~cm}^{2}$. Average value of A was $6,06 \mathrm{~cm}^{3} / 50 \mathrm{~cm}^{2}$. (the results of individual tests were: $5.75,7.13$ and 5.31 $\mathrm{cm}^{3} / 50 \mathrm{~cm}^{2}$ ).

This result ranks CAC into the wear resistance class A6 according to Table, which is given in the handbook for outdoor concrete industrial pavements A82/11 prepared by Belgian Road Research Center (BRRC). This means that the CAC can be used for outdoor surfaces that are loaded with heavy industrial activity, heavy forklifts with pneumatic, full rubber tires or full hard tires with contact pressures up to $4 \mathrm{~N} / \mathrm{mm}^{2}$.

Similarly, the CAC can be classified by description of German Zement-Merkblatt Tiefbau (Industrieböden aus Beton) into the Böhme wear class A6, which field of application is described as: very heavy load, heavy industry, very heavy forklift with solid rubber tires (capacity $\leq 80 \mathrm{kN}$, contact pressure $\leq 2 \mathrm{~N} / \mathrm{mm}^{2}$ ) or solid hard tires (contact pressure $\leq 4 \mathrm{~N} / \mathrm{mm}^{2}$ ).

The abrasion load effects that arise during the grinding wear test and underwater abrasion test are so different that it is difficult to find a correlation between the results of the two tests. Investigations of different types of concrete have shown that there is a poor correlation between the results of the underwater abrasion test and the grinding wear test according to the Böhme method $[12,13]$.

\subsubsection{Underwater abrasion resistance of already damaged CAC}

After improvement of underwater abrasion resistance of undamaged $\mathrm{CAC}$, there was still question of the resistance of already damaged $\mathrm{CAC}$, which can be expected in the practice. Therefore, $10 \mathrm{~mm}$ wide notch of the 38-day-old CAC (Figure 9) and $1 \mathrm{~mm}$ wide notch of the 105-day-old CAC (Figure 11), through all thickness of the coating, had been made cross the diameter of specimen surface.

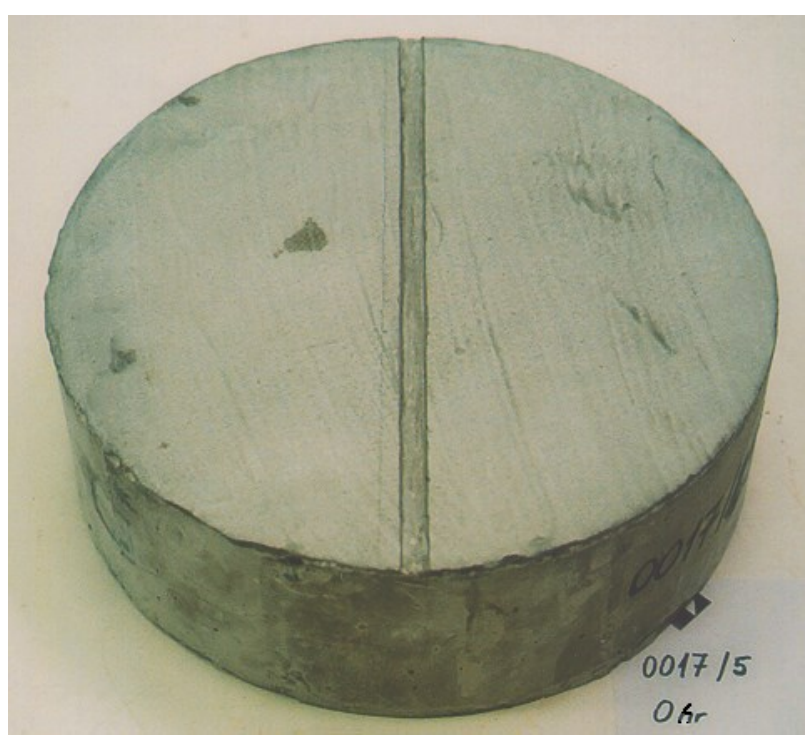

Fig. 9. The 38-day-old CAC with $10 \mathrm{~mm}$ wide notch before the test

38-day-old CAC was gradually removed only in the area of the notch in the direction of rotation of water and steel balls (Figure 10).

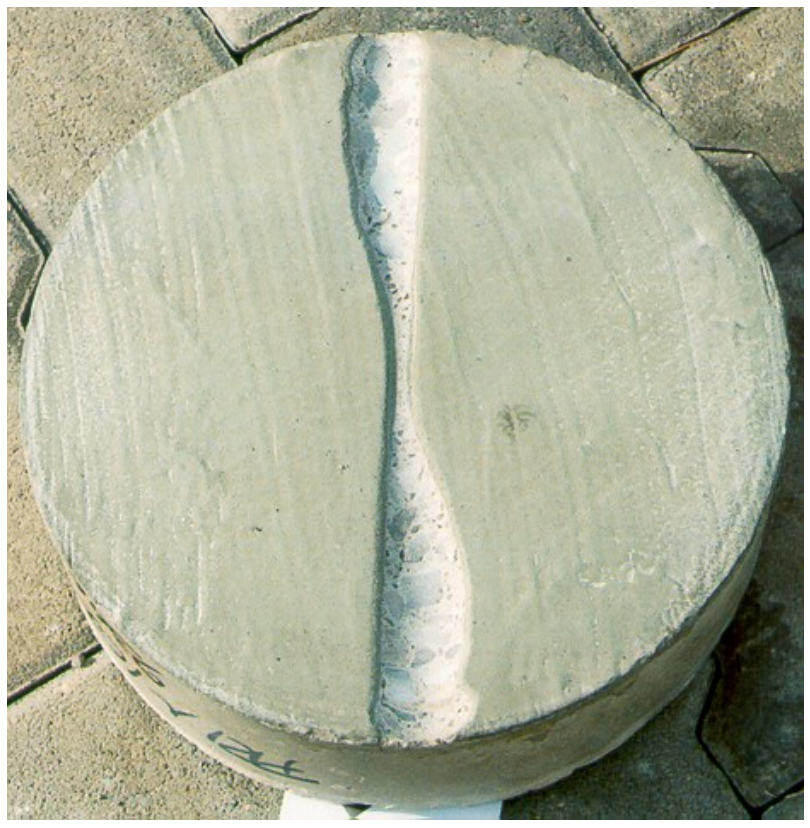

Fig. 10. The 38-day-old CAC with $10 \mathrm{~mm}$ wide notch at the end of the test 
In addition to $\mathrm{CAC}$, concrete was worn in the vicinity of the notch with water-borne steel balls. The surface portion of the removed CAC was $10.8 \%$ at the end of the test (after 72 hours), which is about 3 times more than the surface without notch $(3.2 \%$, see chapter 3.2.1).

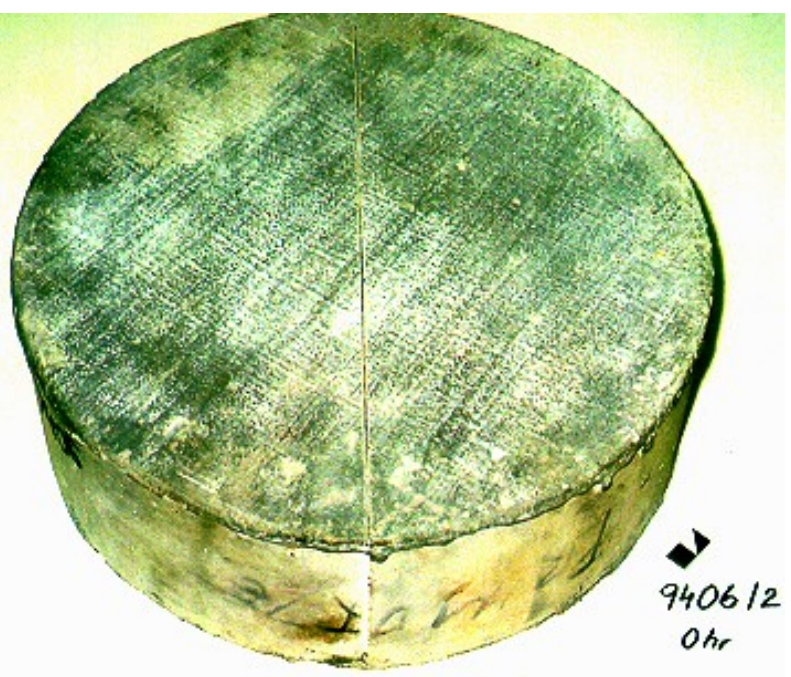

Fig. 11. The 105-day-old CAC with $1 \mathrm{~mm}$ wide notch before the test

Already from the visual comparison of the surface of the removed 102-day-old CAC without a notch (Figure 7) and the surface of the removed 105-day-old CAC with a $1 \mathrm{~mm}$ wide notch (Figure 12), it is clear that the very narrow notch has no effect on the underwater abrasion resistance of CAC. The surface portion of the removed CAC with a notch $(3.09 \%)$ is even smaller compared to the surface potion of the removed CAC without a notch $(5.37 \%)$.

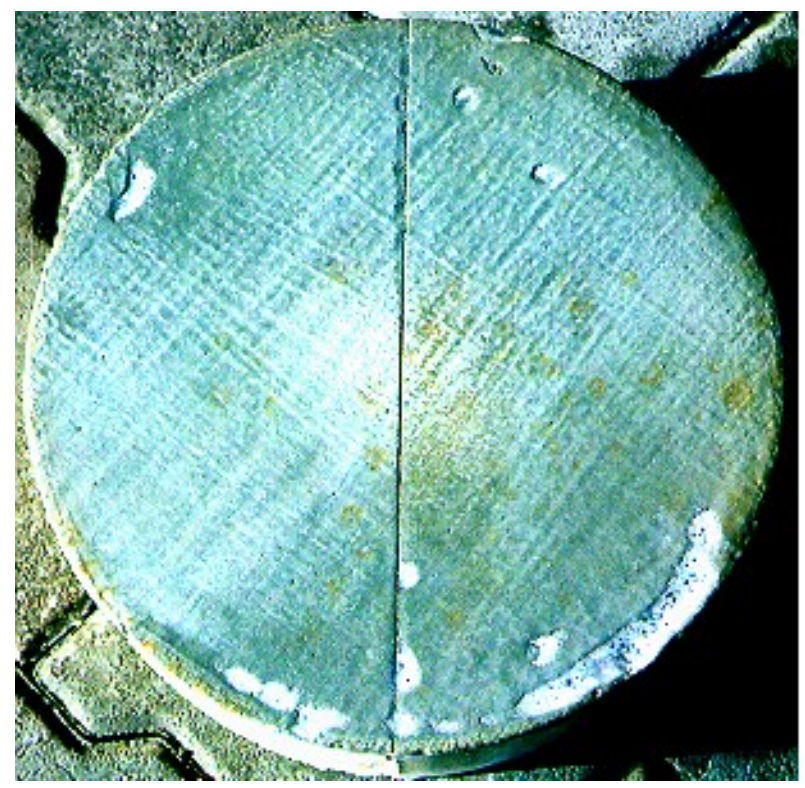

Fig. 12. The 105-day-old CAC with $1 \mathrm{~mm}$ wide notch at the end of the test

\subsubsection{Influence of underwater abrasion loading on bond between CAC and concrete surface}

Bond strength of the CAC on concrete surface was measured with Pull-off test method given in EN 1542 Products and systems for the protection and repair of concrete structures - Test methods - Measurement of bond strength by pull - off. The drilling depth in the concrete substrate was about $10 \mathrm{~mm}$. Bond strength of the 7-day-old CAC was measured on different measuring points on the site. Average value of bond strength was $0.93 \mathrm{~N} / \mathrm{mm}^{2}$ (minimal strength was $0,7 \mathrm{~N} / \mathrm{mm}^{2}$ and maximal strength was $1.2 \mathrm{~N} / \mathrm{mm}^{2}$ ). The major part of failures was happened in the cohesive mode. $80 \%$ of average failure area passed through the $\mathrm{CAC}$, through the interface between two layers of the CAC, in particular. This is evident from Figure 13, which shows a cohesive failure at two measuring points. Remained part $(20 \%)$ of average failure area passed through the interface between the $\mathrm{CAC}$ and concrete surface (adhesive failure).

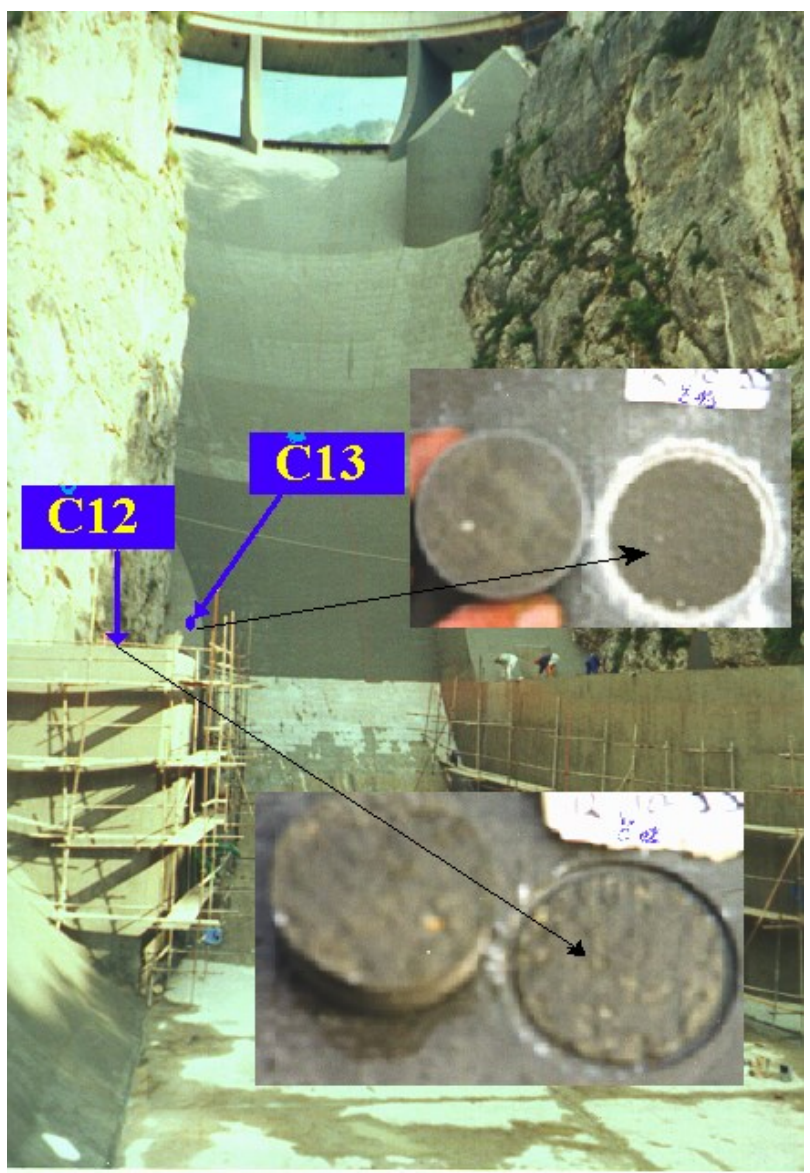

Fig. 13. Cohesive failure during Pull-off test on two measuring points on the site

Further investigation of the bond strength of the CAC was carried out in a laboratory on cylinder test specimens used for the underwater abrasion test. Pull-off tests were carried out on the following CACs:

-30-day-old CAC before underwater abrasion test (30 BUWAT), 
- 38-day-old CAC with notch after underwater abrasion test (38-n A-UWAT),

- 102-day-old CAC after underwater abrasion test (102 A-UWAT).

The results of the tests are shown in Table 1.

Table 1. Results of CAC Pull-off tests.

\begin{tabular}{|c|c|c|c|c|c|}
\hline \multirow{2}{*}{ CAC } & \multicolumn{3}{|c|}{$\begin{array}{c}\text { Bond strength } \\
\left(\mathrm{N} / \mathrm{mm}^{2}\right)\end{array}$} & \multicolumn{2}{c|}{$\begin{array}{c}\text { Average portion } \\
\text { of failure mode } \\
(\%)\end{array}$} \\
\cline { 2 - 6 } & Avg. & Min. & Max. & cohesive & $\begin{array}{c}\text { adhesi } \\
\text { ve }\end{array}$ \\
\hline $\begin{array}{c}\text { 30 B- } \\
\text { UWAT }\end{array}$ & 1.5 & 1.4 & 1.5 & 92.5 & 7.5 \\
\hline $\begin{array}{c}\text { 38-n A- } \\
\text { UWAT }\end{array}$ & 1.5 & 1.5 & 1.6 & 97.5 & 2.5 \\
\hline $\begin{array}{c}\text { 102 A- } \\
\text { UWAT }\end{array}$ & 2.2 & 2.1 & 2.3 & 85.0 & 15.0 \\
\hline
\end{tabular}

The results of the Pull-off tests indicate that the bond strength between the CAC and the concrete surface is increased by increasing the age of the CAC, and the abrasion load of water-bearing steel balls does not reduce the bond strength of the $\mathrm{CAC}$. The increase in the bond strength as a function of the age of the CAC is shown in Figure 14. It is also evident that the notch in the CAC does not affect the bond strength.

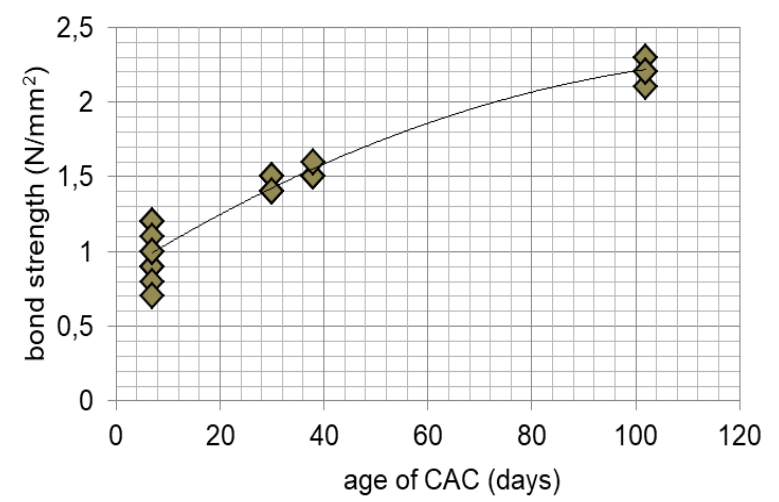

Fig. 14. Bond strength as a function of the age of the CAC

The failure mode is the same in all the cases given in Table 1. The largest portion belongs to cohesive failure (Figure 15). It is similar to the failure mode found in the 7-day-old CAC tests on the site.

\subsubsection{Impact of capillary water pressure on adhesion strength and underwater abrasion resistance of CAC}

Resistance of CAC to pressure of capillary water was measured in regard to the proposed method by Hillemeier et al (14) on the samples for underwater abrasion test. The specimens were putted in water after 28 days of CAC application, so that the water level extended up to $1,0 \mathrm{~cm}$ under interface between the CAC and concrete surface. The specimens were kept in water for 30 days. Meantime, surface of the CAC had been visual observed continuously. No visible lift of the CAC was determined.

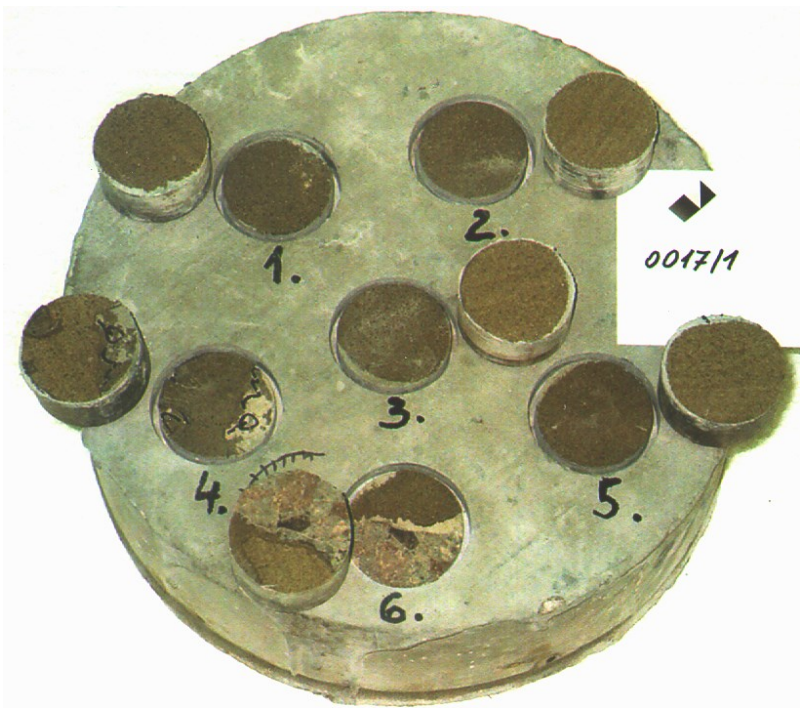

Fig. 15. Predominantly cohesive failure mode of the 30 day-old CAC before the underwater abrasion test (30 BUWAT)

Therefore, bond strength between the CAC and concrete surface of first specimen was measured with Pull-off test method after the end of test of CAC resistance to pressure of capillary water. On the second specimen, the underwater abrasion resistance of CAC was first tested and then the bond strength between the $\mathrm{CAC}$ and the concrete surface was tested on the same specimen.

Pull-off tests were carried out on the following CACs:

- 58-day-old CAC after the test of resistance to pressure of capillary water ( 58 A-RPCWT),

-58-day-old CAC after the test of resistance to pressure of capillary water and after the underwater abrasion test (58 A-RPCWT-UWAT),

The results of the tests are shown in Table 2.

Table 2. Results of CAC Pull-off tests after capillary water pressure test.

\begin{tabular}{|c|c|c|c|c|c|}
\hline \multirow{2}{*}{ CAC } & \multicolumn{2}{|c|}{$\begin{array}{c}\text { Bond strength } \\
\left(\mathrm{N} / \mathrm{mm}^{2}\right)\end{array}$} & \multicolumn{2}{c|}{$\begin{array}{c}\text { Average portion of } \\
\text { failure mode (\%) }\end{array}$} \\
\cline { 2 - 6 } & Avg & Min & Max & $\begin{array}{c}\text { cohesiv } \\
\mathrm{e}\end{array}$ & $\begin{array}{c}\text { adhesiv } \\
\mathrm{e}\end{array}$ \\
\hline $\begin{array}{c}58 \mathrm{~A}- \\
\text { RPCW } \\
\mathrm{T}\end{array}$ & 1.1 & 0.9 & 1.2 & 4.0 & 96.0 \\
\hline $\begin{array}{c}58 \mathrm{~B}- \\
\text { RPCWT- } \\
\text { UWAT }\end{array}$ & 0.8 & 0.5 & 1.1 & 76.0 & 24.0 \\
\hline
\end{tabular}

If results of bond strength given in Table 2 are compared with results of bond strength of the 30-day-old CAC, which had been not tested before (Table 1), moderate decrease of bond strength is obtained (Figure 16). 


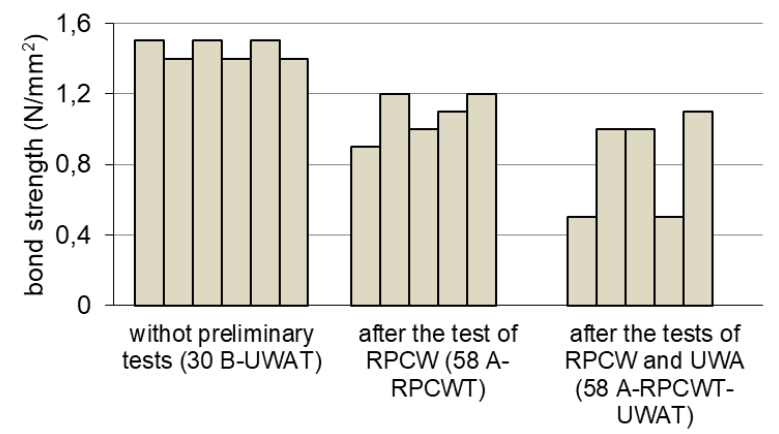

Fig. 16. Influence of the capillary water pressure and reciprocal influence of the capillary water pressure and underwater abrasion on the bond strength between the $\mathrm{CAC}$ and the concrete surface

However, in assessing the results shown in Figure 16, it should be taken into account that various failure mode was obtained at the end of the Pull-off tests (Figure 17).

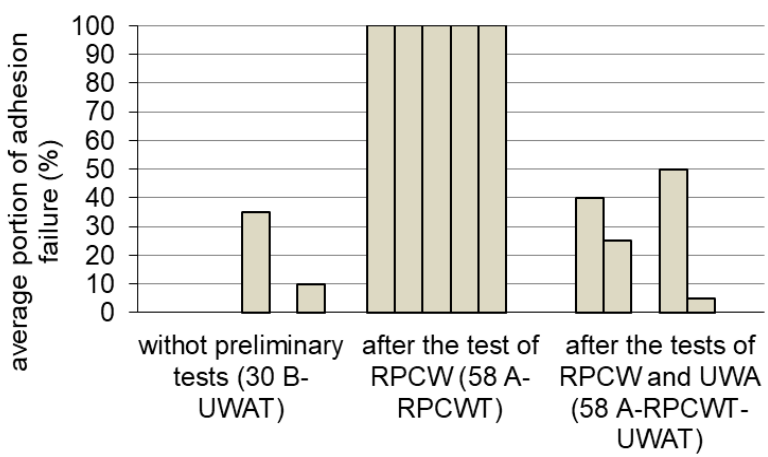

Fig. 17. Influence of the capillary water pressure and reciprocal influence of the capillary water pressure and underwater abrasion on the average portion of adhesion failure

At the end of the Pull-off tests of the 30-day old CAC before the underwater abrasion test (30 B-UWAT), predominantly cohesive failure mode were obtained. A $92.5 \%$ average potion of the cohesive failure mode is achieved and only $7.5 \%$ is the average proportion of the adhesive failure mode (Figures 17 and 15).

Pure adhesive failure $(100 \%$ average potion of the adhesive failure mode) was obtained at the end of the Pull-off test of 58-day-old CAC after the test of resistance to pressure of capillary water (58 A-RCWT) (Figures 17 and 18).

A predominantly cohesive failure mode was obtained again at the end of the Pull-off test of 58-day-old CAC after the test of resistance to pressure of capillary water and underwater abrasion test (58 A-RPCWT-UWAT). A $76.0 \%$ average potion of the cohesive failure mode is achieved and $24.0 \%$ is the average proportion of the adhesive failure mode (Figure 17). No damage was observed on the CAC surface during and after the underwater abrasion test. The surface portion of the removed CAC was $0 \%$ at the end of the test (Figure 19).

From the results obtained, it can be concluded that the water-borne steel balls reduce only the bond between the two layers of CAC in such a way that the bond strength decreases and cohesive failure mode occurs at the end of the Pull-off test.

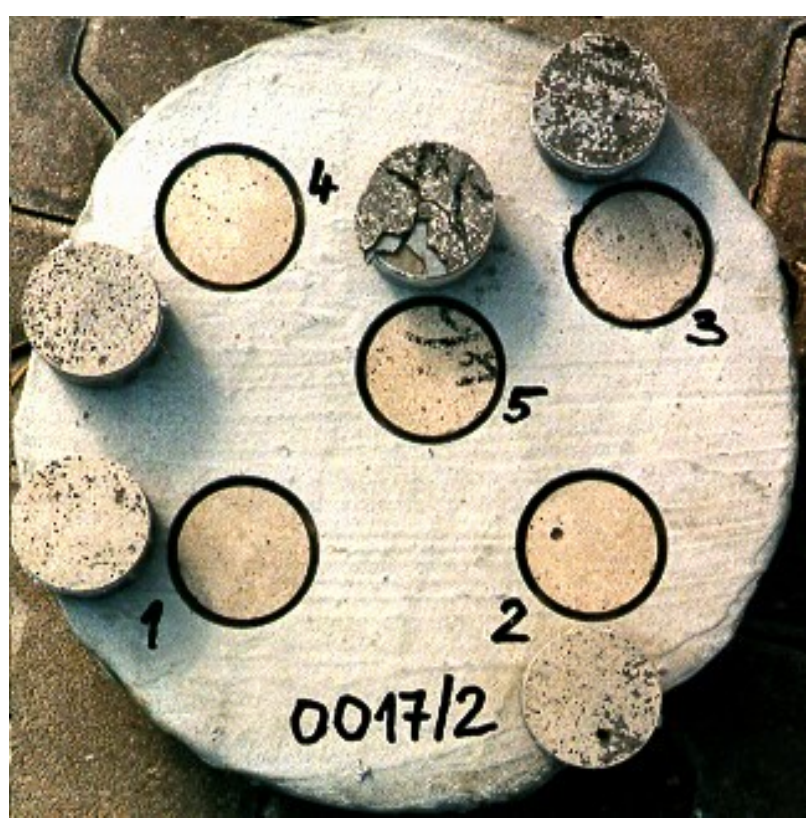

Fig. 18. Pure adhesion failure mode of 58-day-old CAC after the test of resistance to pressure of capillary water (58 A-RPCWT)

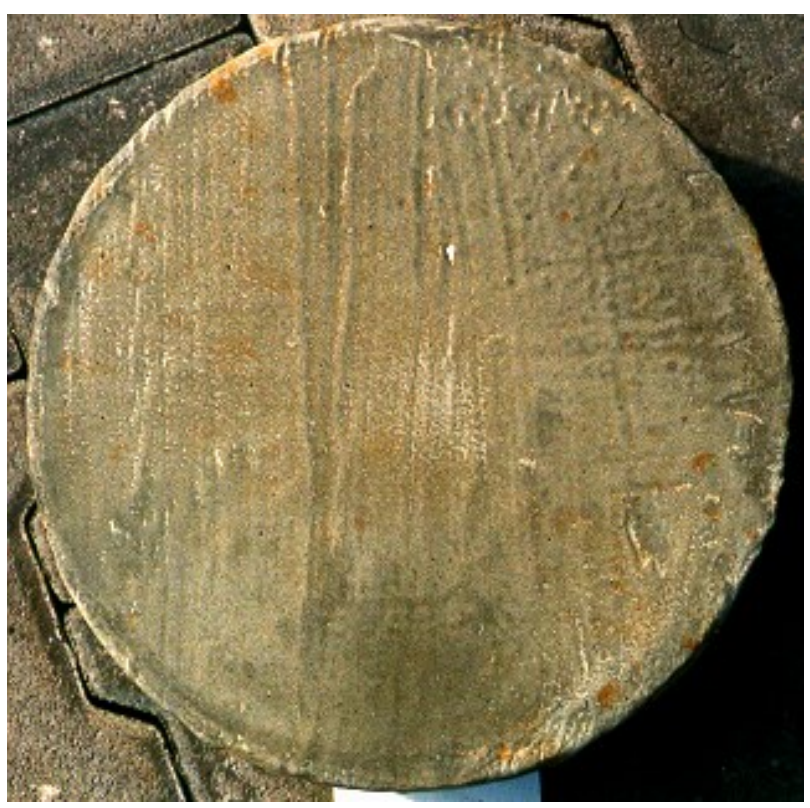

Fig. 19. Undamaged surface of 58-day-old CAC (58 ARPCWT-UWAT) at the end of underwater abrasion test

During the operation of the power plant, the water continuously or occasionally flows over the dam and is always present in the stilling basin. Therefore, water comes under CAC due to capillary pressure or in places where CAC is partially removed by underwater abrasion. In winter, this water freezes and the freeze/thaw cycling starts, resulting in additional CAC removal.

This phenomenon was detected during the test of CAC surface resistance to freeze - thaw in accordance with method given in Slovenian standard SIST 1026 Concrete - Specification, performance, production and conformity - Rules for the implementation of SIST EN 206, Appendix NE. The resistance of the surface of the 111-day-old CAC to freeze - thaw was measured on 
three test specimens with an area of $150 \times 150 \mathrm{~mm}$ up to 30 cycles. The surfaces of all specimens were coated with freezing medium ( $3 \% \mathrm{NaCl}$ solution) at a thickness of 3 to $5 \mathrm{~mm}$ throughout the test. One cycle lasts 24 hours. The temperature profile of the cyclising in the programmable climatic cabinet is taken from SIST 1026, and it is shown in Figure 20, where required borders of single stages of one cycle are drawn, together with the temperature of the surface, measured and recorded by a temperature sensor. Quantity of scaled material was measured every 5 cycles. Obtained average results of depth of spalling $(0.02 \mathrm{~mm})$ and loss of mass $(0.004$ $\mathrm{mg} / \mathrm{mm}^{2}$ ) are much lower than required values up to 30 cycles (the greatest depth of spalling has to be lover than $1.0 \mathrm{~mm}$, loss of mass per unit area of test face has to be lover than $0.2 \mathrm{mg} / \mathrm{mm}^{2}$ ).

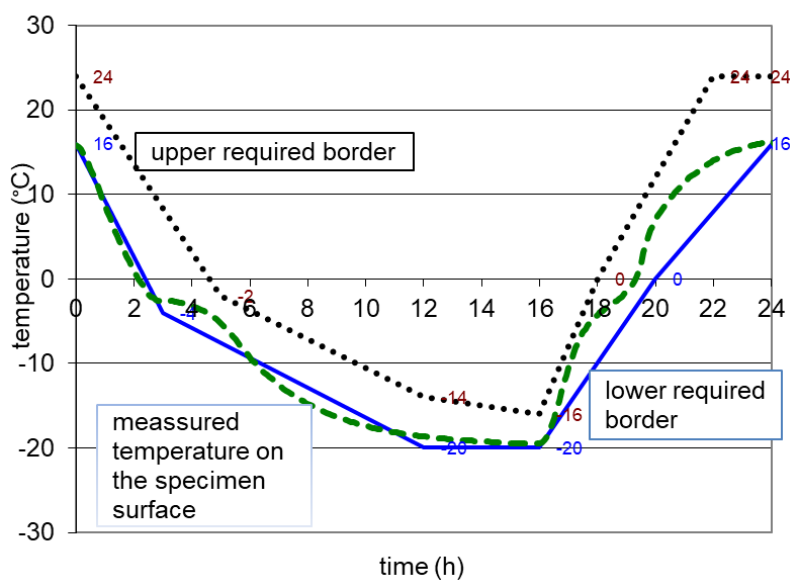

Fig. 20. One cycle of the temperature profile of the cyclising in the programmable climatic cabinet

Despite the excellent resistance of the CAC, it was separated from the concrete surface in the corner of the third specimen. Due to a small damaged CAC in this corner, the $\mathrm{NaCl}$ solution came under $\mathrm{CAC}$ and it froze during the test and separated the CAC from the concrete surface. This phenomenon was obtain first after 16 cycles, and in the further cycles, up to 20 cycles, unbounded area of CAC increased moderate. It increased for additional $25 \%$ of unbounded area, approximately up to the end of the test - 30 cycles (Figure 21).

\section{Conclusions}

First of all, it can be concluded that relatively good underwater abrasion resistance of the used Cementitious Acrylic Coating (CAC) was obtained. However, with the increasing age of $\mathrm{CAC}$, underwater abrasion resistance decreases. This behavior of CAC is influenced by its ductility. Ductile behavior was obtained during the bending test of $\mathrm{CAC}$, but with the aging of the CAC ductility also decreased.

Other properties of the CAC such as compressive strength and bond strength between the CAC and concrete surface increase with the age of CAC, in the meantime ultimate flexural strength remained unchangeable.

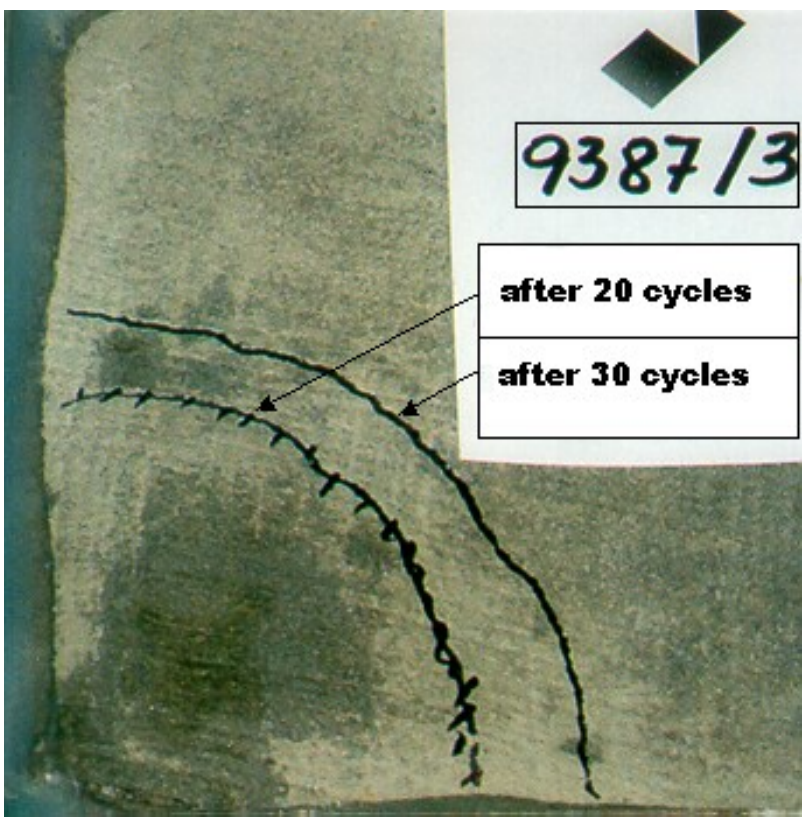

Fig. 21. Increase of unbounded area of the CAC up to 30 cycles

Pressure of capillary water decreases bond strength between CAC and concrete surface. With additional load with waterborne abrasion particles, the bond strength continues to decrease.

When using CAC on the dam and stilling basin, water can be present under the CAC due to capillary pressure or in places where CAC is partially removed by underwater abrasion. This water freezes and the freeze/thaw cycling starts in the winter, resulting in additional CAC removal. This phenomenon was detected during the test of CAC surface resistance to freeze thaw.

Rather similar behavior of CAC, applied on the dam and stilling basin of power-plant Moste, was obtained after 1 year of application.

\section{References}

1. ACI 548.3R, Rep. on Poly.-Mod. Concr. ACI Man. of Cocr. Prac. (2017)

2. Liu, T.C. Tech Rep. No. C-78-4, U.S. Army Eng. Waterw. Exper. Stat. (1980)

3. Liu, T.C. ACI J., Sept.-Oct., pp. $341-350$, (1981)

4. Hester, W.T., Khayat, K.H. and Gerwick, Jr., B.C., ACI SP 114, V. 1, pp. 713 - 731, (1989)

5. Liu, T.C. and McDonald, J.E., Cem., Concr. and Aggr., 2 (3), pp. 93 - 100, (1981)

6. Šušteršič, J., Mali, E. and Urbančič, S., ACI SP 126, V. 2, pp. 729 - 743, (1991)

7. Šušteršič, J., RILEM Proc., no. 17, pp. 860 - 871, (1992)

8. Berra M., Ferrara G. and Tavano S., ACI SP 114, V. 2, pp. $827-847,(1989)$ 
9. Kryžanowski, A., Mikoš, M., Šušteršič, J. and Planinc, I., ACI mat. J., V. 106, no. 4, pp. 349 - 356, (2009)

10. Kryžanowski, A., Mikoš, M., Šušteršič, J., Ukrainczyk, V. and Planinc, I., J. Mech. Eng., V. 58, no. 4, pp. 245 - 254 (2012)

11. Šušteršič, J., Zajc, A., Leskovar, I. and Dobnikar, V., ICPIC 2010 Proc., pp. 289 - 297, (2010)
12. Šušteršič. J., Komel, M., Hudej, M. and Zajc, A. Comp. in Constr., pp. 385 - 389, (2001)

13. Šušteršič, J., Kryžanowski, A. and Zajc, A., Con Mat., pp. 63 - 77, (2005)

14. Hillemeier, B., Stenner, R. and Flohrer, C., BetoKalender, pp. 595 - 720, (1999) 